\title{
Performance Evaluation of Waste Polyethylene and PVC on Hot Asphalt Mixtures
}

\author{
Md. Nobinur Rahman ${ }^{1 . *}$, Mohammad Ahmeduzzaman ${ }^{2}$, M. A. Sobhan ${ }^{1}$, T. U. Ahmed ${ }^{1}$ \\ ${ }^{1}$ Department of Civil Engineering, Rajshahi University of Engineering \& Technology, Rajshahi, Bangladesh \\ ${ }^{2}$ Department of Civil Engineering, Stamford University Bangladesh, Dhaka, Bangladesh \\ *Corresponding author:mnrahmanruet@gmail.com
}

Received April 24, 2013; Revised June 19, 2013; Accepted June 20, 2013

\begin{abstract}
Since the forefront invention of Polyethylene and Polyvinyl chloride (PVC), it has been spasmodically used in every possible purpose which is biologically non-degradable and has a blimp environmental problem leading astringent environmental impact. Nevertheless, for such property of sustainability the polyethylene and PVC have been reused in the field of transportation engineering for enhancing the property of asphalt binder, since for having a desirable binding property. At the same time the recycling of waste polyethylene and PVC can save disposal sites and reduce the amount of inert drawn from quarries. In this investigation, waste polyethylene and PVC as the sort of polymer is used to investigate the potential prospects to enhance asphalt mixture properties and to check the design criteria of asphalt mixture using this two modifier at optimum binder content. The investigation concentrated on the test of modified binder properties and Marshall mix design was used, first to determine the optimum binder content and then further to test the modified mixture properties. The tests include the determination of unit weight, stability, flow and voids characteristics. Some of the measured properties of asphalt mixture with the modifier used in this study were within the acceptable recommended limits. On the basis of experimental results, it is concluded that the asphalt mixtures with waste polyethylene modifier up to $10 \%$ and waste PVC modifier up to $7.5 \%$ can be used for flexible pavement construction in a warmer region from the standpoint of stability, stiffness and voids characteristics.
\end{abstract}

Keywords: waste polyethylene, hot asphalt mixtures, Marshall test, voids characteristics, optimum binder content

Cite This Article: Nobinur Rahman, Md., Mohammad Ahmeduzzaman, M. A. Sobhan, and T. U. Ahmed, "Performance Evaluation of Waste Polyethylene and PVC on Hot Asphalt Mixtures." American Journal of Civil Engineering and Architecture 1, no. 5 (2013): 97-102. doi: 10.12691/ajcea-1-5-2.

\section{Introduction}

The proportion as well as the properties of the components (binder, aggregate and additive) into the design mix of Asphalt concrete greatly depends on its performance. Among them, the binder is of relatively more important which can be normal penetration grade bitumen as well as it can be modified by adding an optimum proportion of different additives. Recently, many studies have been attempted by adding different materials as an additive to improve the mechanical and physical properties of asphalt concrete. Polymers is one of these additives. Bitumen can be improved by the addition of polymers in stiffness and the temperature susceptibility point of view $[1,2]$. The rutting resistance of the mixture has been observed to be increased by the improvement of stiffness in hot climates and the stiffness enhancement allows the use of relatively softer base bitumen, which sequentially, provides a better low temperature performance. The improved adhesion and cohesion property has also been observed in consequence of the applying polymer modified binders [3]. High density polyethylene (HDPE) can also be used as a modifier of asphalt concrete and this modified binder become more resistant to permanent deformation and it contributes to recirculation of plastic wastes as well as the solid waste disposal problem is relatively solved [4]. Researchers have been found that, with the addition of some waste materials and certain polymers to asphalt binders can improve the performance of asphalt concrete $[5,6]$.

In this investigation, waste polyethylene and PVC as the sort of polymers is used to investigate the potential prospects to enhance asphalt mixture properties and to check the design criteria of asphalt mixture using this two modifier at optimum binder content. The amount of waste polyethylene and PVC is increasing day by day as the availability of these two wastes is enormous. More or less all the solid waste is being mixed with Municipal Solid Waste over land area after some nominal sorting and thus thrown over the land area named landfill. Since the plastic, polyethylene and PVC is non-biodegradable, it remains at the site for uncertain time causing the appreciable amount of waste increase into the landfill, ultimately increasing amount of cost for waste disposal. Since the present disposal method is either by land filling or by incineration, the waste plastic is owed dispose likely that causing adverse impact on the environment. To encounter this trend, considerable effort is being put into recycling waste, turning it into re-usable by products. Waste polyethylene and PVC derived from local market, household wastes, 
domestic and commercial uses. Waste polyethylene and $\mathrm{PVC}$ on heating melt at around $100^{\circ} \mathrm{C}$ to $260^{\circ} \mathrm{C}$. Moreover, the molten polyethylene and PVC has a binding property. Hence, the molten polyethylene and PVC materials can be used as a binder and they can be mixed with binder like bitumen to enhance their binding property. These two may be a good modifier for the bitumen, used for road construction. Many investigations have found that the strength of the paving mixes can be enhanced by the use of a binder formed by modifying available bitumen with certain additives like Sulphur and organic polymer. The modified polymers also improve temperature susceptibility and viscosity characteristics. Modified bitumen containing $10 \%$ waste polyethylene can be used in the road construction particularly in the warmer region [7]. Low-density polyethylene carry bags collected from domestic solid waste can be used as the modification of $80 / 100$ paving grade bitumen [8]. Bitumen can be mixed with waste polyethylene terephthalate which acts as an additives [9]. Moreover, a comparative performance has also been investigated using $8 \%$ and $15 \%$ waste plastic/polymer by wt. of bitumen with conventional bituminous concrete mixes prepared with 60/70 penetration grade bitumen [10]. The principle objectives of this investigation is to:

- Find out the changing properties of the hot asphalt mix after mixing of polyethylene and PVC

- Check the modified binder is suitable or not for road construction

- Determine the optimum percent of asphalt, polyethylene and PVC in the hot asphalt mix.

\section{Materials and Methods}

In this investigation, polyethylene and PVC used as modifier on asphalt mixtures. To evaluate the performance of polyethylene and PVC on hot asphalt mixtures crushed black stone that are collected from Panchagarh, Bangladesh used as coarse aggregate. Fine aggregate portion of the aggregate blend was taken from Domar sand which is collected from the northern part of Bangladesh. The fines from sand and stone dust finer than $0.075 \mathrm{~mm}$ were used as filler material in this study. A considerable amount of stone dust is produced during crushing and some stone dust remains in crushed stone. These are mixed with fine sand for proper utilization of stone dust.

\subsection{Polyethylene}

Polyethylene has been the most popular plastic which has been used so far. Moreover, it is a semi-crystalline polymeric material having a well fatigue, wearing as well as chemical resistance and a wide range of properties. This polyethylene is available in local markets in Bangladesh in the form of a bag with various colors. In this investigation, white color of low density polyethylene bags were used which were collected from local market and domestic wastes. This polyethylene was then cleaned properly and shredded to form the size of the particle 2-3 $\mathrm{mm}$ for the preparation of the recycled polyethylene. Specific gravity and melting temperature of the polyethylene used in this investigation were 0.94 and $115^{\circ} \mathrm{C}$ [7].

\subsection{Polyvinyl Chloride (PVC)}

Polyvinyl chloride (PVC), a thermoplastic material, has widely been used in construction works for being cheap, durable and easy workability. For the present study, waste PVC was collected from domestic waste, mineral water bottles, credit cards, toys, pipes and gutters, electrical fittings, furniture, folders and pens, medical disposables etc. and then cleaned properly for the preparation of recycled PVC. This waste PVC was then shredded in a shredding machine to form the size of the particle is about 2-3 mm. The specific gravity of the waste PVC used in this study was 1.25 .

\subsection{Bituminous Materials}

The binding material, 80/100 penetration grade bitumen, has been collected from Eastern Refinery, Bangladesh. Routine test as per AASHTO were performed on the bitumen samples to evaluate the bitumen properties were: Specific gravity, Ductility, Flash point \& fire point, Penetration, Softening point and Solubility. The properties of bitumen binder, which are presented in Table 1, were within the specification of penetrating bitumen grade $80 / 100$.

Table 1. Properties of used bituminous binder

\begin{tabular}{|c|c|}
\hline Properties & Test results \\
\hline Specific gravity & 1.023 \\
\hline Ductility $(\mathrm{cm})$ & 115 \\
\hline Flash point $\left({ }^{\circ} \mathrm{C}\right)$ & 295 \\
\hline Fire point $\left(\left({ }^{\circ} \mathrm{C}\right)\right.$ & 305 \\
\hline Solubility $(\%)$ & 97.93 \\
\hline Softening point $\left({ }^{\circ} \mathrm{C}\right)$ & 52.5 \\
\hline Penetration $(0.1 \mathrm{~mm})$ & 83 \\
\hline
\end{tabular}

\subsection{Aggregates}

In this investigation the crushed black stone was used as a coarse aggregate which were broken into pieces manually in $25.00 \mathrm{~mm}$ downgrade. Particles retained on $2.36 \mathrm{~mm}$ sieve were regarded as coarse aggregate [11]. A fine aggregate portion of the aggregate blend (passes 2.36 $\mathrm{mm}$ and retained on $0.075 \mathrm{~mm}$ sieve) was taken from coarse sand. Non-plastic sand finer than $0.075 \mathrm{~mm}$ sieve was used as mineral filler [7]. Apparent specific gravity of the filler was 2.63. Properties of aggregates are given in Table 2.

Table 2. Properties of aggregates

\begin{tabular}{|c|c|c|}
\hline Properties & Coarse Aggregate & Fine Aggregate \\
\hline Bulk specific gravity & 2.79 & 2.46 \\
\hline Apparent specific gravity & 2.86 & 2.66 \\
\hline Water absorption, \% & 0.81 & 3.10 \\
\hline Impact Test, \% & 6 & $\ldots$ \\
\hline Loss Angeles Abrasion, \% & 12 & $\ldots$ \\
\hline
\end{tabular}

\subsection{Gradation of Aggregates}

In order to investigate the behavior of the asphalt concrete mix modified with additives, a continuously graded aggregate of bituminous macadam is needed. In the continuously graded bituminous macadam, in order to obtain a dense mix with a controlled optimum air void content, the uniform gradation of the aggregate blend is required, hence to construct a stable and durable flexible 
pavement [12]. The gradation of aggregates in asphalt mixes in the present investigation is shown in Figure 1.

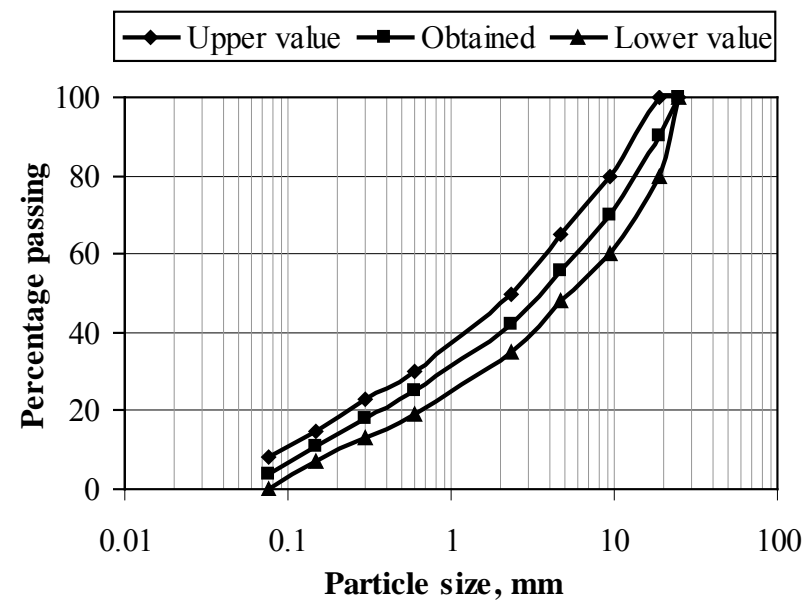

Figure 1. Grain size distribution of aggregate gradation

\subsection{Preparation of Marshall Specimen}

To investigate the Marshall stability of asphalt mixes with polyethylene and PVC, specimens of $101.6 \mathrm{~mm}$ diameter and approximately $63.5 \mathrm{~mm}$ thickness were prepared. The test procedure introduced by Bruce Marshall and developed by the U.S corps of engineers has been followed in the laboratory investigations. Initially about $1200 \mathrm{~g}$ of aggregates was taken to prepare the specimen of $101.6 \mathrm{~mm}$ (4 inch) diameter and $63.5 \mathrm{~mm}$ (2.5 inch) thick for pure bitumen and three specimens were prepared for each bitumen content. Five bitumen content was used starting from $4.5 \%$ with increment of $0.5 \%$ to determine the optimum bitumen content for the pure bitumen and the optimum bitumen content (OBC) was $5.4 \%$. This bitumen content $(5.4 \%)$ was kept constant for preparing the further specimen, only changing the percentage of polyethylene and PVC content. Then, sixteen bowls for preparing sample was weighted for both polyethylene and PVC. Hot pure bitumen was poured into those bowls. The weight of the bitumen was taken. The polyethylene and PVC were weighted with respect to 2.5, $5,7.5,10,12.5,15,17.5$ and $20 \%$ weight of pure bitumen separately. The samples were prepared one after another. At first the bitumen for $2.5 \%$ polyethylene and PVC were heated till it fully liquefied separately and was in a state to dissolve polyethylene and PVC. The polyethylene bags and PVC were gradually left in bitumen. The softened form of the polyethylene bags was floating on the hot bitumen. But after continuous stirring by steel spoon it was thoroughly mixed with the bitumen. There was a little change in color. This mother sample is kept for further experiments. Thus, eight samples were prepared with variable polyethylene content and another eight samples were prepared for PVC content. Now, for the preparation of Marshall specimens of $101.6 \mathrm{~mm}$ diameter and approximately $63.5 \mathrm{~mm}$ thick, about $1200 \mathrm{gms}$ of aggregates of all sizes were weighted and taken in a pan. The aggregate blend was then heated for four hours in an electric oven maintained at a temperature of $182-188^{\circ} \mathrm{C}$ (depending on the moisture content of that aggregates). The aggregates were then transferred to a hot mixing bowl and thoroughly mixed. A crater was formed in the middle of the dry blended aggregate and the required amount of bitumen $(5.4 \%$ pure bitumen + various $\%$ of polyethylene/PVC content by the weight of bitumen), heated to a steady temperature of $160^{\circ} \mathrm{C}$ (on the basis of Saybolt Furol viscosity of bitumen) was added. The aggregates and modified bitumen were mixed to yield a mixture having a uniform distribution of modified bitumen. The mould assembly heated in a bath of boiling water was placed on the table and a piece of circular paper of $101.6 \mathrm{~mm}$ diameter was placed at the bottom of the mould. The entire bath of mixture was then introduced in the mould and the mixture was vigorously spaded with a hot trowel 15 times around the perimeter and 10 times over the interior. Temperature of the mixture was recorded and the mould assembly with the mixture was placed on the standard compaction pedestal and 50 blows were applied with the $4.5 \mathrm{~kg}$ compaction hammer with a free fall of $45.7 \mathrm{~cm}$. The axis of the hammer was kept perpendicular to the base of the mould assembly during compaction. The number of blows for the preparation of the sample was selected corresponding to $690 \mathrm{kN} / \mathrm{m}^{2}(100$ psi) tyre pressure. The heavy vehicles which move on the road of Bangladesh have tyre pressure in range of 415-485 $\mathrm{kN} / \mathrm{m}^{2}$ (60-70 psi). So the assumption of $690 \mathrm{kN} / \mathrm{m}^{2}$ tyre pressure seems to be safe and appropriate. The collar of the mould was then removed and the mould with specimen inside was inverted and reset on the base plate. The extension collar was placed in position and 50 blows were applied on the face of specimen with the compaction hammer. The sample was then cooled for about 10 minutes and extruded from the mould with the help of a hydraulic jack. The specimen was then transferred to a smooth flat surface and allowed to stand overnight at room temperature. The same procedure was adopted to prepare specimens of all percentage of polyethylene and PVC content.

\section{Test Results}

\subsection{Effects of Polyethylene and PVC on Properties of Bitumen}

The molten polyethylene and PVC were homogeneously mixed with the hot asphalt mix but the excess percentage of polyethylene and PVC cause the segregation of these from hot mix. The penetration and ductility value decreases with the increase of polyethylene content which makes modifying binder more harder. By adding polyethylene and PVC the purity of the bitumen decreases so that the solubility of modified bitumen decreases. Due to the lower melting point of polyethylene and PVC, the flash point and fire point of the modified binder decreases with the increase of polyethylene and PVC content. The specific gravity of the binder decreases with the increase of polethylene content due to the lower specific gravity of polyethylene but increases with the increase of PVC content due to the higher specific gravity of PVC. On the other hand the softening point value increases with the increase in polyethylene and PVC content due to the higher soften temperature of both polyethylene and PVC. The properties of bitumen after modifying with polyethylene shown in Table 3 and after modifying with PVC shown in Table 4. 
Table 3. Properties of bitumen with Polyethylene

\begin{tabular}{|c|c|c|c|c|c|c|c|c|}
\hline \multirow{2}{*}{ Properties } & \multicolumn{7}{|c|}{ Percentage of Polyethylene } \\
\cline { 2 - 9 } & 2.5 & 5 & 7.5 & 10 & 12.5 & 15 & 17.5 & 20 \\
\hline Penetration $(0.1 \mathrm{~mm})$ & 76 & 71 & 66 & 59 & 53 & 49 & 45 & 39 \\
\hline Ductility $(\mathrm{cm})$ & 85 & 77 & 67 & 55 & 49 & 41 & 38 & 34 \\
\hline Solubility $(\%)$ & 95.44 & 89.25 & 85.2 & 82.8 & 79.55 & 76.98 & 73.13 & 69.91 \\
\hline Flash point $\left({ }^{\circ} \mathrm{C}\right)$ & 280 & 265 & 240 & 230 & 210 & 190 & 175 & 165 \\
\hline Fire point $\left({ }^{\circ} \mathrm{C}\right)$ & 290 & 275 & 250 & 240 & 220 & 200 & 185 & 175 \\
\hline Specific gravity & 1.0145 & 1.0085 & 1.004 & 0.998 & 0.995 & 0.992 & 0.987 & 0.985 \\
\hline Softening point $\left({ }^{\circ} \mathrm{C}\right)$ & 55 & 59 & 61 & 66 & 71 & 78 & 81 & 83 \\
\hline
\end{tabular}

Table 4. Properties of bitumen with PVC

\begin{tabular}{|c|c|c|c|c|c|c|c|c|}
\hline \multirow{2}{*}{ Properties } & \multicolumn{8}{|c|}{ Percentage of PVC } \\
\hline & 2.5 & 5 & 7.5 & 10 & 12.5 & 15 & 17.5 & 20 \\
\hline Penetration $(0.1 \mathrm{~mm})$ & 72 & 65 & 60 & 52 & 43 & 32 & 22 & 14 \\
\hline Ductility $(\mathrm{cm})$ & 80 & 65 & 53 & 39 & 25 & 17 & 9 & 6 \\
\hline Solubility (\%) & 85.79 & 71.17 & 59.97 & 51.17 & 43.29 & 34.79 & 27.08 & 20.76 \\
\hline Flash point $\left({ }^{\circ} \mathrm{C}\right)$ & 290 & 275 & 265 & 260 & 250 & 245 & 235 & 220 \\
\hline Fire point $\left({ }^{\circ} \mathrm{C}\right)$ & 305 & 290 & 280 & 265 & 255 & 250 & 240 & 230 \\
\hline Specific gravity & 1.023 & 1.03 & 1.035 & 1.045 & 1.057 & 1.070 & 1.094 & 1.120 \\
\hline Softening point $\left({ }^{\circ} \mathrm{C}\right)$ & 59 & 65 & 73 & 78 & 86 & 92 & 95 & 98 \\
\hline
\end{tabular}

\subsection{Effects of Polyethylene and PVC on Bituminous Mixes}

The result shown in Figure 2 and Figure 3 indicates that the unit weight and stability of the compacted specimen shows an appreciable increasing behavior initially with an increase in percentage of polyethylene and PVC content in bitumen. After reaching to an optimum content of polyethylene and PVC the curve shows a declining behavior. With the increment of polyethylene and PVC on binder, the better compactions were done as a result the unit weight and stability increased. For further increment of modifier on bitumen, the waste polyethylene segregate from hot bitumen as a result unit weight and stability decreased.

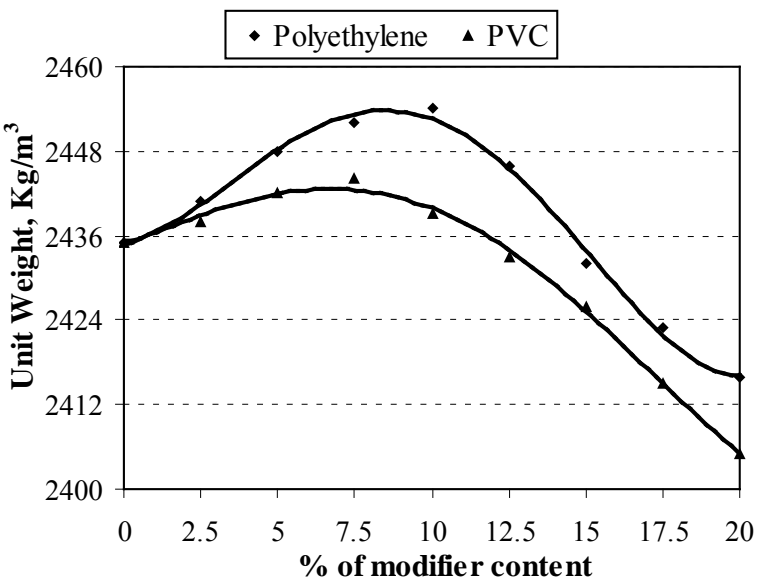

Figure 2. Relationships between unit weight and \% of modifier content

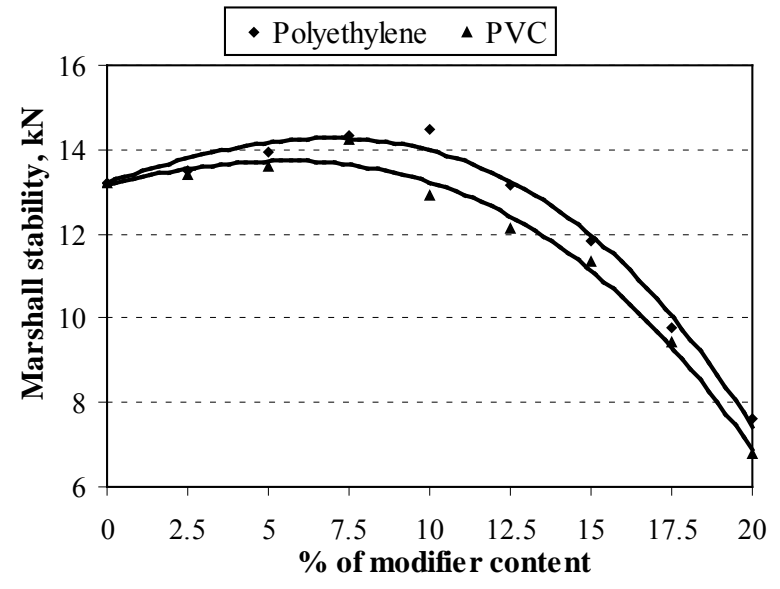

Figure 3. Relationships between Marshall stability and \% of modifier content

Figure 4 shows that the with the increment of polyethylene and PVC content on hot asphalt mix the flow value increases. Marshall Quotient (MQ) is the ratio of stability to flow (stiffness) of the design mix and thus made some relations with tyre pressure which is an indicator of the resistance against the deformation of the asphalt concrete [13]. MQ values are calculated to evaluate the resistance of the deformation of the Polyethylene and PVC modified specimens. A higher value of MQ indicates a stiffer mixture and hence, indicates that the mixture is likely more resistant to permanent deformation [14]. From Figure 4, it is seen the Marshall Quotient are above required value $2.1 \mathrm{kN} / \mathrm{mm}$ up to $10 \%$ of polyethylene content and $7.5 \%$ of PVC content on bitumen binder. 


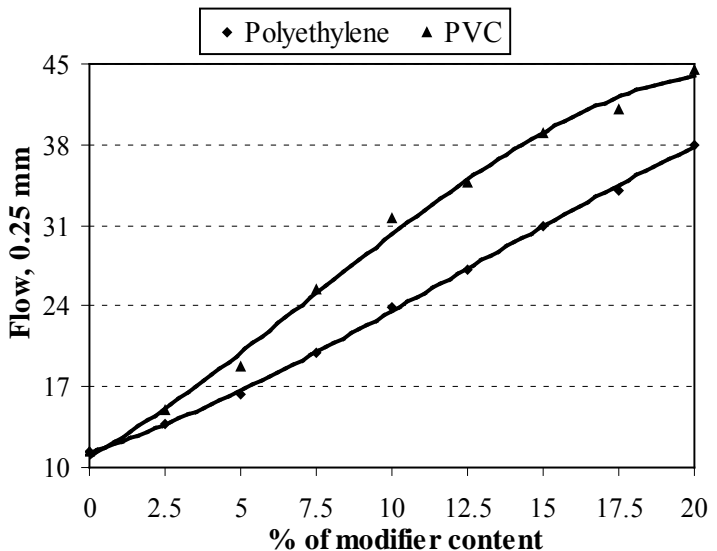

Figure 4. Relationships between flow value and \% of modified content

The void record of the mix with various percentage of polyethylene reported in Figure 5 shows that the Percentage air void in the mix initially decreases with the increase in percentage additives for both polyethylene and PVC on bitumen content conversely the curve recovers i.e. the percentage increases with further increase in additives. It is seen that the all percentage modified binder satisfies the limiting value (3 to $5 \%$ ) of percentage of air voids specified by The Asphalt Institute [11]. Figure 6 shows that the percentage of voids in mineral aggregates initially decreases with the increase of modifier content on bitumen binder. After attain a certain minimum value at $10 \%$ of polyethylene and PVC content the percentage of voids in mineral aggregate increases with the increase in modifier content. According to the Asphalt Institute the minimum value of \%VMA is $12 \%$ and Figure 6 shows that $\% \mathrm{VMA}$ is greater than $12 \%$ for all percentage of modifier content.

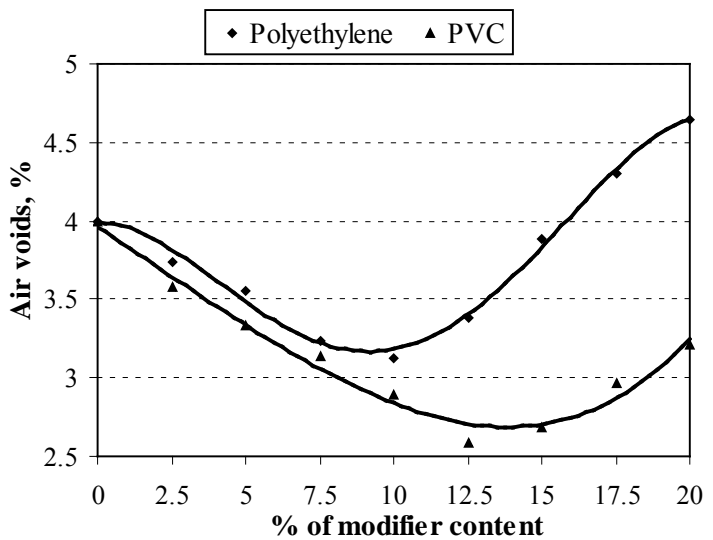

Figure 5. Relationships between air voids and \% of modified content

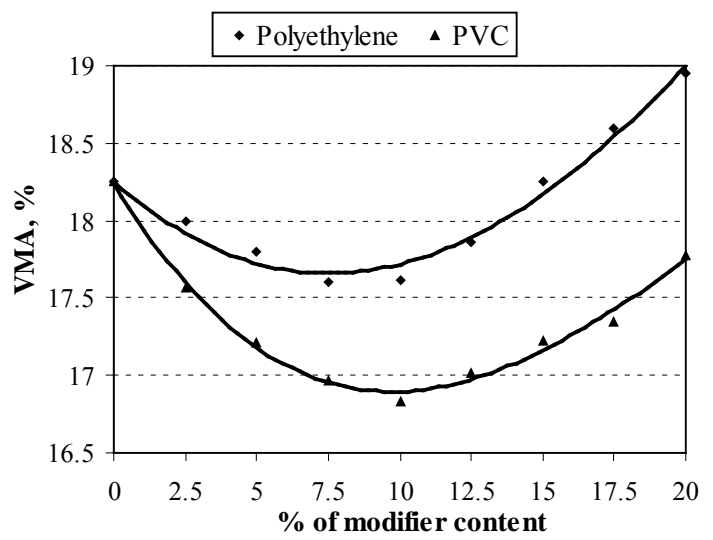

Figure 6. Relationships between $\%$ VMA and $\%$ of modifier content

\subsection{Optimum Modifier Content}

The optimum modifier content is selected as the content that satisfies the following [4]:

- Maximum Unit Weight

- Maximum Marshall Stability

- The closet percentage to Air Voids content of $4 \%$

- Minimum VMA content

The maximum unit weight $2453 \mathrm{Kg} / \mathrm{m}^{3}$ and 2442 $\mathrm{Kg} / \mathrm{m}^{3}$ were reported for waste polyethylene and PVC at a proportion of $10 \%$ and $7.5 \%$ respectively. Moreover, unit weight of hot asphalt mix modified with polyethylene is greater than modified with PVC and without modification. On the other hand, maximum stability $14 \mathrm{kN}$ and $13.6 \mathrm{kN}$ were reported for both types of modifier at a proportion of $10 \%$ and $7.5 \%$ respectively. At a proportion of $10 \%$ and $12.5 \%$ for both polyethylene and PVC have minimum air voids as $3.2 \%$ and $2.58 \%$ respectively. On the other hand, voids in mineral aggregate is lower for PVC modifier than polyethylene. The minimum void in mineral aggregate for polyethylene and PVC modifier is $17.60 \%$ and $16.97 \%$ respectively at a proportion of $7.5 \%$. To conclude, it is possible to say that modifying asphalt mixture with polyethylene enhances its properties more than the improvements realized by utilizing PVC. The optimum polyethylene and PVC content is $10 \%$ and $7.5 \%$ measured by weight of bitumen content. Table 5 shows that the Marshall characteristics of hot asphalt mixtures at optimum modifier content.

Table 5. Marshall characteristics of hot asphalt mixtures at optimum modifier content

\begin{tabular}{|c|c|c|}
\hline \multirow{2}{*}{ Marshall characteristics } & \multicolumn{2}{|c|}{ Modifier type } \\
\cline { 2 - 3 } & Polyethylene & PVC \\
\hline Optimum modifier content $(\%)$ & 10 & 7.5 \\
\hline Maximum unit weight $\left(\mathrm{Kg} / \mathrm{m}^{3}\right)$ & 2453 & 2442 \\
\hline Marshall stability $(\mathrm{kN})$ & 14 & 13.6 \\
\hline Flow $(0.25 \mathrm{~mm})$ & 24 & 25 \\
\hline$\% \mathrm{~V}_{\mathrm{a}}$ & 3.2 & 3.05 \\
\hline$\% \mathrm{VM}$ & 17.7 & 16.9 \\
\hline Marshall Quotient $(\mathrm{kN} / \mathrm{mm})$ & 2.33 & 2.18 \\
\hline
\end{tabular}

\section{Conclusion}

In this investigation it is seen that, penetration, ductility and solubility value of modified asphalt mixture decreased with the increase of polyethylene and PVC modifier on the other hand softening point increases with the increase of modifier. Kalantar et al. studied with the waste polyethylene terephthalate in bituminous binder and they also showed that penetration value decrease and softening point increase with the increment of modifier [9]. Sabina et al. describes the performance of bitumen with the inclusion of plastic/polymer which were $8 \%$ and $15 \%$ by weight of bitumen [10]. Their experimental results indicate that at $8 \%$ plastic/polymer by weight of bitumen gives the better result than $15 \%$ plastic/polymer. Awwad and Shbeeb recommended that the proportion of modifier (high density polyethylene) is $12 \%$ by weight of bitumen can be used in road constructions [4]. In this investigation, polyethylene modifier gives better and satisfactory results than PVC. Specifically, 10\% polyethylene and 7.5\% PVC by weight of asphalt content can be recommended for the construction of flexible pavement. 
On the basis of experimental results of this investigation, the effect of modified bitumen on the behavior of hot asphalt mix is reasonably good from the considerations of Marshall test properties. From the laboratory test it can be concluded that, the dense graded asphalt mix with modified bitumen containing polyethylene up to $10 \%$ and PVC up to $7.5 \%$ can be used for the construction of bituminous roads in warmer region from the view point of stability, stiffness and voids characteristics.

\section{References}

[1] Catt, OV, 2004. Investigation of polymer modified asphalt by shear and tensile compliances. Proceedings of the Annual Conference And Exhibition of the Transportation Association of Canada, September 19-22, 2004, Quebec City, QC., Canada.

[2] Coplantz, JS, Yapp, MT and Finn, FN, 1993. Review of Relationships between Modified Asphalt Properties and Pavement Performance. National Research Council, 2101 Constitution Avenue, NW, Washington DC, USA.

[3] Awwad, MT and Shbeeb, L, 2007. "The Use of Polyethylene in Hot Asphalt Mixtures", American Journal of Applied Sciences, 4(6), 390-396.

[4] Hinislioglu, S and Agar, E, 2004. "Use of waste high density polyethylene as bitumen modifier in asphalt concrete mix", Journal of Materials letters, 58, 267-271.

[5] Little, DN, 1993. Enhancement of Asphalt Concrete Mixtures to Meet Structural Requirements through the Addition of Recycled Polyethylene. Use of Waste Materials in Hot-Mix Asphalt, ASTM
STP 1193, Fred Weller, H. (Ed.). ASTM International, Philadelphia, 210-306.

[6] Jew, P, and Woodhams, RT, 1982. "Polyethylene modified bitumens for paving applications", Proceedings of the Association of Asphalt Paving Technologies 55-82, 541.

[7] Rahman, MN, Sobhan, MA and Ahmed, TU, 2012. "Effects of waste polyethylene on bituminous mixes", Proceedings of the 1st International Conference on Civil Engineering for Sustainable Development, Khulna, Bangladesh.

[8] Punith, VS and Veeraragavan, A, 2010. "Evaluation of reclaimed polyethylene-modified asphalt pavements", ASTM J. Mater. Eval., Vol. 38

[9] Kalantar, ZN, Mahrez, A and Karim, MR, 2010. "Properties of bituminous binder modified with waste polyethylene terephthalate", Proceeding of Malaysian Universities Transportation Research Forum and Conferences, Universiti Tenaga Nasional.

[10] Sabina, Khan, TA, Sangita, Sharma, DK, and Sharma, BM, 2009 "The performance evaluation of waste plastic/polymer modified bituminous concrete mixes", J. Sci. Ind. Res., 68, 975-979.

[11] The Asphalt Institute, 1984. Mix Design Methods for Asphalt Concrete and Other Hot-Mix Types. $6^{\text {th }}$ Edition, Asphalt Institute, Lexington, KY, USA.

[12] Sobhan, MA, Mofiz, SA and Rasel, HM, 2011. "Effect of gradation and compactive effort on the properties of bituminous mixes with waste concrete aggregates", International Journal of Civil and Environmental Engineering, 11(4), 18-21

[13] Whiteoak, D, 1991. "The Shell Bitumen Handbook", Thomas Telford, London, UK.

[14] Roberts, FL, 1991. "Hot Mix Asphalt Materials, Mixture Design and Construction", NAPA Educational Foundation, Auburn, AL., USA, Pages: 490 